\title{
Asymmetric Shocks Inside Future EMU
}

\author{
Michel Beine \\ University of Lillell \\ Alain Hecq \\ M aastricht University
}

\begin{abstract}
In this paper, we focus on the issue of shocks asymmetries in the future Euro pean M onetary Union. Relying on the technique of codependence developed by Gouriéroux and Peaucelle [1989, 1993], we propose a new method which, unlike the analysis of B ayoumi and Eichengreen [1992], does not require any arbitrary restrictions. As a whole, our results support the idea of a two-speed Europe. (JEL Classification: C22, F 33, F42)
\end{abstract}

\section{Introduction}

For a couple of years, the project of forming a E uropean M onetary Union (EMU) has been extensively discussed. B oth the timing and the exact composition of the future EM U have been particularly debated. Quite recently, it has been argued that a complete union with 12 or 15 countries was a non

* Correspondence Address: M ichele Beine, M inistère de la Région Wallonne, Service des Etudes et de la Statistique, Place de Wallonie, 1, 5100 Jambes, Belgium, (Tel) 081-33-3050, (F ax) 081-33-3055, (E-mail) SESM OD3@VM 1.ULG.AC.BE.; Alain Hecq, Department of Quantitative E conomics, M aastricht U niversity, The N etherland; We would like to thank J. Houard, J-M. Zakoian and F. Bismans and three anonymous referees for helpful comments and suggestions as well as the participants of the economic seminar of the universities of Lille I and II. The usual disclaimer applies.

C1997 - Institute for International Economics, Sejong Institution. All rights reserved. 
viable arrangement. Indeed, even in the academic circles, a lot of authors support the idea of a "two-speed Europe" which favors the formation of a restricted monetary union with, for instance, Germany and her small neighbors followed by a later integration of some other countries having reached a satisfactory degree of economic convergence.

On the theoretical side, the plans for EMU have led to a renewal of the old Keynesian theory of optimum currency areas initiated by $M$ undell [1961]. This theory emphasizes some criteria that can be used to assess if a particular geographic area may or may not constitute a currency area. In recent formal models 〈B ayoumi [1994], Ricci [1995]〉, it has been shown once more that the degree of asymmetry of real shocks affecting the constituting countries of the zone is a key determinant of the net benefits drawn from a currency union.

Numerous empirical studies have been conducted to measure the magnitude of asymmetric disturbances between European countries. As shocks are not directly observable, the main problem and consequently the main source of disagreement between authors remain either their identification or the measurement of the degree of asymmetry. Unsurprisingly, this empirical literature has made extensive use of econometric methods which significantly differ from each other.

In this note, we present a new econometric approach aimed at assessing the degree of real shocks asymmetry. The method is based on the concept of codependence developed by Gouriéroux and Peaucelle [1989]. Unlike the structural VAR approach adopted by Bayoumi and Eichengreen [1992] which is considered as the reference paper on the topics, it allows to avoid the imposition of a priori restrictions on the parameters estimates. Section II quickly presents the main empirical studies. Section III provides a brief and intuitive presentation of the codependence technique. Section IV reports the results and emphasizes the limitations of the approach.

\section{Empirical Evaluations of the Degree of Asymmetry}

As a starting point, one can distinguish analyses relying on aggregated data such as GNP or total employment from those dealing with sectoral data. The latter are best illustrated by B ayoumi and Prasad [1995] as well as 
by $\mathrm{Helg}$ et al. [1995]. ${ }^{1} \mathrm{M}$ ost of the empirical analyses rely however on aggregated data.

As suggested by Vaubel [1976], the traditional approach is to analyze the real exchange variability (RER). This has been extensively applied to future EMU. For instance, using the variability of RER among six West German Länders as a yardstick, von Hagen and Neumann [1994] find empirical support to the idea of a two-speed Europe. In the same line of research, DeSerres and Lalonde [1995] attempt to distinguish between nominal and real shocks on the basis of the observed movements of RER. This approach faces, however, some criticisms. As pointed out by Eichengreen [1990], a important limitation is that it fails to distinguish between the effects of the shocks and the speed of adjustment to these shocks.

In order to account for this limitation, B ayoumi and Eichengreen [ 1992] use the structural vector autoregression (VAR) approach to isolating disturbances proposed by Blanchard and Quah [1989]. They identify, with some a priori restrictions on the effect on output and prices, ${ }^{2}$ supply and demand shocks across EC countries and US regions. Correlations between the computed disturbances provide some information about their symmetric nature, while the impulse response functions associated to the VAR give some insight into the speed of adjustment to these shocks.

Table 1 presents the main results of the literature in terms of the optimal composition of the future EMU. As a whole, this literature supports the idea of a two-speed Europe which discriminates between a core of countries hit by similar disturbances and a periphery, with some countries considered as intermediate cases. ${ }^{3} \mathrm{~N}$ ever theless, there is no consensus about the exact composition of these groups. ${ }^{4}$

1. In particular, Helg et al. [1995] analyze the correlations between innovations of industrial production of 11 European countries on the basis of a cointegrated VAR. They distinguish between country-specific shocks, industry-specific shocks and local shocks.

2. These restrictions are however consistent with a simple aggregate supply and demand framework.

3. In a recent analysis, Rubin and Thygesen [1996] challenge this view.

4. Excepted for Belgium and the Netherlands which are generally expected to form a hard core with Germany. 
Table 1

Optimal Composition of E MU on the Basis of Shock Asymmetries ${ }^{6}$

\begin{tabular}{|l|l|l|l|l|}
\hline \multicolumn{1}{|c|}{ Analysis } & \multicolumn{1}{c|}{ M ethod } & \multicolumn{1}{c|}{ Core } & Periphery & Intermediate \\
\hline $\begin{array}{l}\text { von Hagen and } \\
\text { Neumann [1994] }\end{array}$ & $\begin{array}{l}\text { Real Exchange Rate } \\
\text { Variability }\end{array}$ & $\begin{array}{l}\mathrm{Ge}, \mathrm{Au}, \mathrm{Be}, \mathrm{Ne}, \\
\mathrm{Fr}\end{array}$ & & It, Dk, UK \\
\hline $\begin{array}{l}\text { DeSerres and } \\
\text { Lalonde [1995] }\end{array}$ & $\begin{array}{l}\text { Real Exchange Rate } \\
\text { Variability }\end{array}$ & $\mathrm{Ge}, \mathrm{Be}, \mathrm{Ne}$ & Sw, Fr, It & UK, Sp \\
\hline Helg et al. [1995] & $\begin{array}{l}\text { Sectoral Data / } \\
\text { Cointegrated VAR }\end{array}$ & $\begin{array}{l}\mathrm{Ge}, \mathrm{Be}, \mathrm{Ne}, \mathrm{Dk}, \\
\mathrm{Fr}, \mathrm{UK}\end{array}$ & It, Sp & Gr, Ir, Pr \\
\hline $\begin{array}{l}\text { Bayoumi and } \\
\text { Eichengreen [1992] }\end{array}$ & Structural VAR & $\begin{array}{l}\mathrm{Ge}, \mathrm{Be}, \mathrm{Ne}, \mathrm{Dk}, \\
\mathrm{Fr}\end{array}$ & & $\begin{array}{l}\text { UK, It, Sp, } \\
\text { Ir, Pr, Gr }\end{array}$ \\
\hline $\begin{array}{l}\text { Artis and Zhang } \\
\text { [1995] }\end{array}$ & $\begin{array}{l}\text { Correlations between } \\
\text { Cyclical Components }\end{array}$ & $\begin{array}{l}\mathrm{Ge}, \mathrm{Be}, \mathrm{Fr}, \mathrm{Ne}, \\
\mathrm{Sp}, \mathrm{Pr}, \mathrm{It}\end{array}$ & $\mathrm{Ir}$ & UK \\
\hline
\end{tabular}

\section{Asymmetric Shocks and Codependence}

The main default of the analysis of Bayoumi and Eichengreen [1992] is that the decomposition in supply and demand disturbances is based on arbitrary restrictions. Therefore, we propose an approach which does not require any a priori restriction on the data. We rely on the concept of codependence developed by Gouriéroux and Peaucelle [1989, 1993] and apply it to bilateral time series processes characterizing unemployment and real interest rates of several European economies.

Codependence techniques allow to account for long run relationships between stationary variables. The analysis is carried out in terms of dynamic multipliers and shock persistence in a multivariate moving average framework. We skip here the technical issues and, in particular, the estimation procedure. ${ }^{7}$ In order to get some insight into this approach, consider the fol-

5. Countries codes: $\mathrm{Ge}=\mathrm{Germany}, \mathrm{Be}=\mathrm{B}$ elgium, $\mathrm{Ne}=\mathrm{T}$ he Netherlands, $\mathrm{Fr}=\mathrm{France}$, $\mathrm{Au}=$ Austria, $\mathrm{Dk}=\mathrm{D}$ enmark, $U \mathrm{~K}=\mathrm{U}$ nited Kingdom, It=ltaly, $\mathrm{Sp}=S$ pain, $\mathrm{Pr}=$ Portugal, $\mathrm{Sw}=$ Switzerland, $\mathrm{Gr}=\mathrm{G}$ reece, $\mathrm{Ir}=$ / reland.

6. The cyclical components are defined as deviations from a deterministic trend which is determined by a wide range of methods including the well-known HoldrickPrescott decomposition.

7. The details can be found in Gouriéroux and Peaucelle [1989]. The behavior of the 
lowing bivariate M A process of order $\mathrm{k}$, for $\mathrm{k}=2$ :

$$
\left[\begin{array}{l}
Y_{1, t} \\
Y_{2, t}
\end{array}\right]=\left[\begin{array}{c}
1, t \\
2, t
\end{array}\right]+\left[\begin{array}{cc}
21 & 22 \\
21 & 22
\end{array}\right]\left[\begin{array}{c}
1, t-1 \\
2, t-1
\end{array}\right]+\left[\begin{array}{cc}
21 & 22 \\
21 & 22
\end{array}\right]\left[\begin{array}{l}
1, t-2 \\
2, t-2
\end{array}\right]
$$

Premultiplying by a vector $[1-\alpha]$, this process reduces to a bivariate white noise. In this case, the order of reduction in the shocks persistence which is called the order of codependence (denoted b) is equal to 2 . The existence of the vector $[1-\alpha]$ implies that in the long run, the two variables $Y_{1, t}$ and $Y_{2, t}$ move towards an equilibrium defined by $Y_{1, t}-\alpha Y_{2, t}=\varepsilon_{1, t}-\alpha \varepsilon_{2, t}$ in which shocks adjust instantaneously. ${ }^{8}$

In order to evaluate the degree of shocks asymmetry in such a bivariate framework, one can estimate the normalized codependence vector [ $1-\alpha]$ and measure how far it lies from the hypothetical vector [ $1-1]$ which is indicative of a symmetric (long run) evolution. In order to measure this distance, one may use, by analogy with the $R^{2}$, the following statistics $D$ :

$$
D=\left[\cos \left(45^{\circ}-\operatorname{arctg}(\alpha)\right)\right]^{2} .
$$

Furthermore, it is important to pay attention to the value of $k-b$ which is indicative of the speed of adjustment of shocks. ${ }^{9}$ Estimates as well as test statistics are a solution of a standard canonical cor relations problem.

\section{Results and Limitations}

The procedure is applied to several European countries in a bivariate framework. Like in the Bayoumi and Eichengreen [1992] analysis, we choose Germany as the reference country. The analysis focuses here on the behavior of two macroeconomic variables which are expected to trace back

tests statistics in small samples is considered in Beine and Hecq [1996]. For a survey of scalar components models (suited for general reduction in ARM A ( $p, q)$ models) whose codependence and common features are a particular case, see Hecq [1997].

8. Cases in which a linear combination does not yield a white noise but leads to a decrease in the VMA order are called non synchronous common cycles by Vahid and Engle [1993].

9. From a purely statistical point of view, a low degree of codependence may be indicative of a spuriously estimated codependence relationship due to problems of power. 
the effects of aggregate real shocks, i.e. variations of unemployment rates and short run (ex-post) real interest rates. ${ }^{10}$ We use quarterly data. While the latter are found to be stationary on the estimation period (79Q2-94Q 4) using the usual ADF unit root tests, ${ }^{11}$ the unemployment rates expressed in levels exhibit a stochastic trend. In this case, in order to prevent important power losses, it is advised 〈Beine and Hecq [1996]〉 to check for the existence of a cointegrating relationship between the variables in level. From the usual Johansen [1988] maximum likelihood procedure (not reported here to safe place), it comes out that for the estimation period (70Q 2-93Q4), the variables are not cointegrated.

Tables 2 and 3 present the results of the procedure. For each pair of countries, the tables report the value of $k^{12}$, i.e. the order of the starting VMA

\section{Table 2}

Test of Codependence - Variations of Unemployment Rates

\begin{tabular}{|l|l|c|c|c|}
\hline 70Q2-93Q4 & $k$ & $k-b$ & $\begin{array}{c}\text { Estimated } \\
\text { Codependence Vector }\end{array}$ & $\mathrm{D}$ \\
\hline $\mathrm{Ge} / \mathrm{Be}{ }^{13}$ & 6 & 2 & {$[1-0.634]$} & 0.951 \\
$\mathrm{Ge} / \mathrm{Fr}$ & 4 & 2 & {$[1-2.95]$} & 0.803 \\
$\mathrm{Ge} / \mathrm{UK}$ & 6 & 4 & {$[1-1.38]$} & 0.974 \\
$\mathrm{Ge} / \mathrm{Dk}$ & 5 & 4 & {$[1-1.78]$} & 0.072 \\
$\mathrm{Ge} / \mathrm{It}$ & 4 & 1 & {$[1-1.90]$} & 0.912 \\
$\mathrm{Ge} / \mathrm{Ne}$ & 5 & 2 & {$[1-0.69]$} & 0.966 \\
$\mathrm{Ge} / \mathrm{Ir}$ & 5 & 2 & {$[1-0.45]$} & 0.872 \\
$\mathrm{Ge} / \mathrm{Sp}$ & 5 & 5 & none & - \\
$\mathrm{Ge} / \mathrm{Pr}$ & 4 & 4 & none & - \\
\hline
\end{tabular}

10. Data sources: unemployment rates: standardized unemployment rates, OECD B usiness Sectoral $D$ ata Bank; prices: consumer price indexes, OECD main indicators; interest rates: 3-months interbank loans, mean values, National Bank of B elgium. The inflation rates were seasonally adjusted using exponential smoothing.

11. This result is also found by Kugler and Neusser [1993].

12. This value is chosen as to avoid underestimation of the VMA order which may induce in small samples important power losses \&see on this point Beine and Hecq [1996]>.

13. Estimation period: $70 Q 2-92 Q 4$. 
Table 3

Test of Codependence - Real Interest Rates

\begin{tabular}{|c|c|c|c|c|}
\hline 79Q 2 - 94Q 4 & k & $k-b$ & $\begin{array}{c}\text { Estimated } \\
\text { Codependence Vector }\end{array}$ & D \\
\hline $\mathrm{Ge} / \mathrm{Be}$ & 3 & 1 & {$\left[\begin{array}{ll}1 & -1.47\end{array}\right]$} & 0.964 \\
\hline $\mathrm{Ge} / \mathrm{Fr}$ & 7 & 6 & {$\left[\begin{array}{ll}1 & 0.291\end{array}\right]$} & 0.231 \\
\hline Ge/ UK & 4 & 4 & none & - \\
\hline $\mathrm{Ge} / \mathrm{Dk}^{14}$ & 6 & 3 & {$\left[\begin{array}{ll}1 & -0.384\end{array}\right]$} & 0.833 \\
\hline $\mathrm{Ge} / \mathrm{It}$ & 5 & 1 & {$\left[\begin{array}{ll}1 & -2.38\end{array}\right]$} & 0.855 \\
\hline $\mathrm{Ge} / \mathrm{Ne}$ & 3 & 1 & {$\left[\begin{array}{ll}1 & -1.09\end{array}\right]$} & 0.998 \\
\hline $\mathrm{Ge} / \mathrm{Sp}$ & 4 & 3 & {$\left[\begin{array}{ll}1 & -0.205\end{array}\right]$} & 0.695 \\
\hline
\end{tabular}

process, the value of $k-b$, i.e. the number of quarters the variables need to adjust towards the equilibrium relationship, the estimated vector and $D$, the measure of the distance from the hypothetical vector [ $1-1]$.

From these results, we can try to draw some conclusions in terms of composition of future EMU and compare them with the results reported in section II.

For a first group of countries constituted by Belgium, the $\mathrm{N}$ etherlands and Italy, our results do not produce any evidence of significant asymmetric disturbances with Germany. For these countries, the order of persistence of the innovations is quite small. For Belgium and the Netherlands especially, the estimated codependence vectors are very close from the hypothetical one [ $1-1]$ and the remaining persistence is relatively small.

For another group constituted by Spain and Portugal, our analysis concludes in favor of the existence of asymmetric disturbances. This is especially true for the analysis conducted for the changes in unemployment rates. To the extent that changes of unemployment rates are also a good proxy for global demand, this could suggest the presence of asymmetric demand shocks.

Finally, for countries like France, the UK and Denmark, the analysis concludes in favor of the existence of an asymmetric behavior in one of the two variables which have been investigated. This is the case for Denmark with

14. Estimation period: 80Q 1-94Q4. 
respect to the variations of unemployment and for France and the UK for the analysis of real interest rates. On this basis, one may classify these countries as intermediate cases among the potential participants to EMU.

As a whole, these results confirm the idea of core-periphery distinction between the candidates to $\mathrm{EMU}$ which is in general supported by the empirical literature. Like in most of the previous studies, the small neighbors of Germany, i.e. Belgium, the Netherlands and to a less extent Austria are found to belong to the core. However, in terms of exact composition of the groups, our results are quite different from those of Bayoumi and Eichengreen [1992] which classify France as a core country and Italy as a peripheral one. ${ }^{15}$ This may confirm the view that as, a whole, the empirical literature implementing the theory of optimum currency areas has been so far rather inconclusive in terms of optimal composition of future $\mathrm{EM} \mathrm{U}\langle\mathrm{De}$ Grauwe [1996]>.

Finally, it is worth mentioning two important limitations of our approach. First, as illustrated by the analysis of the variations of unemployment, this method is not appropriate when the variables expressed in levels are cointegrated. Second, bivariate results may not be appropriate since EM U will be a multi-country currency area. ${ }^{16}$ Ideally, the method should investigate multicountry codependence to determine the exact size of the currency zone. These two points have been tackled in a recent analysis carried out by Rubin and Thygesen [1996] who rely on the notion of serial correlation common features developed by Engle and Kozicki [1993]. While interesting, this method yields results which have to be interpreted with caution. ${ }^{17}$

15. N ote that in a recent analysis which tries to construct optimum currency areas indexes, Bayoumi and Eichengreen [1996] come to the opposite conclusion.

16. See De Grauwe [1996] on this point.

17. Basically, Rubin and Thygesen [1996] combine cointegration and codependence relationships applied to industrial production and prices in a multivariate set up. The concept of codependence is nevertheless rather different from ours. Actually, they look for serial correlation common features, i.e. for linear combinations which reduce the number of autoregressive terms. This in turn impedes a clear interpretation of the results in terms of shocks persistence which is offered by our approach. Indeed, if a linear combination of a starting $\operatorname{VAR}(p)$ process is not a white noise but just a VAR $(p-q)$, both processes admit an infinite VM A representation 


\section{References}

Artis, M . et W. Zhang [1995], "International Business Cycles and the ERM :

Is there a European Business Cycle?," CEPR Discussion Paper, No. 1191.

Bayoumi, T. [1994], "A F ormal M odel of Optimum Currency Areas," CEPR Discussion Paper, No. 968, June.

Bayoumi, T. and B. Eichengreen [1992], "Shocking Aspects of European M onetary Unification," CEPR Discussion Paper, N o. 643, M ay.

Bayoumi, T. and B. Eichengreen [1996], "Ever Close to Heaven ? An Optimum-Currency-Area Index for E uropean Countries," Paper Presented ESEM , Istanbul.

Bayoumi, T. and E. Prasad [1995], "Currency Unions, Economic Fluctuations and Adjustment: Some Empirical Evidence," CEPR Discussion Paper, No. 1172, M ay.

B eine, M . and A. Hecq [1996], "Inference on Codependence: Some M onte Carlo Simulations and Applications," Paper Presented at the ESEM, Istanbul.

Blanchard, O. and D. Quah [1989], "The Dynamic Effects of Demand and Supply Disturbances," American Economic Review, 79; pp. 655-73.

De Grauwe, P. [1996], "The Prospects of a M ini Currency Union in 1999," CEPR Discussion Paper, No. 1458, September.

DeSerres, A. and R. Lalonde [1995], "Les sources des fluctuations des taux de change et leurs implications pour l'union monétaire," Recherches Economiques de Louvain, Vol. 61, No. 1; pp. 3-42.

Eichengreen, B. [1990], "One Money for Europe? Lessons from the U.S. Currency Union," E conomic Policy, No. 10, April.

Engle, R.F. and S. Kozicki [1993], "Testing for Common Features (with comments), Journal of Business and Economic Statistics, Vol. 11; pp. 369395.

Gouriéroux, Ch and I. Peaucelle [1989], "Detecting a Long Run Relationship (with an Application to the PPP Hypothesis)," CREST Working Paper, No. 8902.

Gouriéroux, Ch and I. Peaucelle [1993], "Séries codépendantes: application à I'hypothèse de parité du pouvoir d'achat," in "M acroéconomie, Dévelop- 
pements Récents," Malgrange P. et Salvas-Bronsard, L.(eds), Econo mica; pp. 285-306.

von Hagen, J. and M. Neumann [1994], "Real Exchange Rates Within and Between Cur rency Areas: How Far Away is EM U?," Review of E cono mics and Statistics, Vol. 76; pp. 236-244.

Hecq, A. [1997], "Common Features, Codependence \& Co.," Unpublished $M$ anuscript, $M$ aastricht University.

Helg, R., P. M anassa, T. M onacelli and R. Rovelli [1995], "How M uch (a) symmetry in Europe? Evidence from Industrial Sectors," European E conomic Review, Vol. 39; pp. 1017-1041.

J ohansen, S. [1988], "Statistical Analysis of Cointegration Vectors," Journal of Economic Dynamics and Control, Vol. 12; pp. 231-254.

Kugler, P. et K. N eusser [1993], "International Real Interest Rate Equalization: A M ultivariate Time-Series Approach," J ournal of Applied Econo metrics, No. 8; pp. 163-174.

M undell, R. [1961], "A Theory of Optimum Currency Areas," American Eco nomic Review, Vol. 51; pp.715-25.

Ricci, L.A. [1995], "A Simple Model of an Optimum Currency Area," Proceedings of J ournées de l'AFSE, Intégration E conomique Européenne, Nantes, June.

Rubin, J. and N. Thygesen [1996], "M onetary Union and the Outsiders: A Cointegration-Codependence Analysis of Business Cycles in Europe," Economie A ppliquée, Vol. 49, No. 3; pp. 123-171.

Vahid, F. and R.F. Engle [1993], "Non-Synchronous Common Cycles," USCD Discussion Paper.

Vaubel, R. [1976], "Real Exchange Rate Changes in the European Community: the Empirical Evidence and Its Implications for European Currency Unification," Weltwirtschaftliches Archiv, Bd. 112; pp. 429-470. 